\section{Some hibernating bats like it hot}

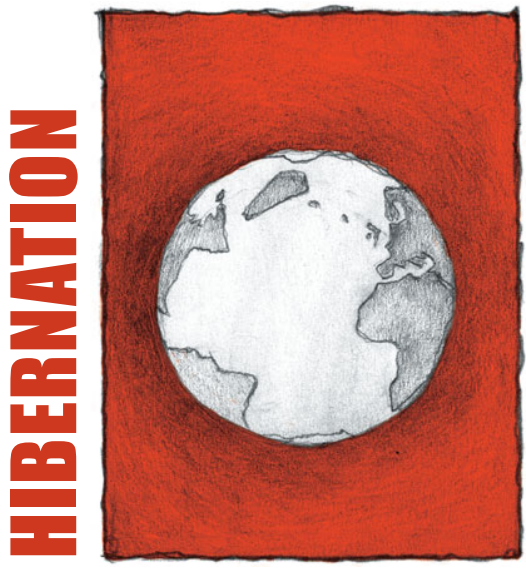

Hibernation, for most of us, conjures up images of woodchucks, marmots and bears curled up in their cold caves for the winter. Derived from the Latin hibernare, meaning 'to pass the winter', the term hibernation has now shifted to include any time when an animal is in a torpid state (where metabolic rate and body temperature are lowered to a fraction of what they are in an active animal) for more than a few days. However, hibernation has also been observed in a number of species from warm climates, including the egg-laying echidnas, marsupials and lemurs, which hibernate anywhere from cold burrows to relatively warm tree-hollows and show a variety of body temperature patterns. Eran Levin and his colleagues from Tel-Aviv University, Israel, have now added two species of cave-dwelling mouse-tailed bats to the roll-call of warm hibernators in their recent Proceedings of the Royal Society $B$ paper. They show that these bats specifically choose to roost and hibernate in the warmest most humid parts of the caves that they inhabit near the Sea of Galilee.

Heated by geothermal activity, sections of the caves selected by the bats remain above $20^{\circ} \mathrm{C}$, and close to $100 \%$ relative humidity, for most of the winter, providing a stable thermal environment. Previously, the researchers had observed that the mouse-tailed bats fatten considerably before the winter and, unlike other small species in the same cave system, the bats were not observed foraging again until the spring. They therefore believed it likely that these bats hibernated through the winter. To confirm their hypothesis, the scientists fitted the bats with tiny temperaturesensitive data loggers that recorded skin temperature for a few weeks at a time. They also measured the resting metabolism of individual bats over a range of ambient temperatures to find out whether the animals ever entered torpor.

The team saw that the bats' body temperatures remained close to the cave temperature throughout the study period and their laboratory metabolic rate measurements confirmed that the bats were entering torpor at these low body temperatures. Interestingly, the researchers found that the metabolic rates were lowest, and therefore the energy savings were optimised, at around $20^{\circ} \mathrm{C}$, which is the average temperature of the bats' chosen winter habitat. They hypothesized that this may be the result of a diet high in saturated fats and relatively low in polyunsaturated fatty acids (which are believed to allow hibernators to lower their body temperatures below $20^{\circ} \mathrm{C}$ ).

The researchers also reported a couple of other fairly novel characteristics of hibernation in these bats. The first is that even when torpid the bats responded to external stimuli, calling and showing signs of movement when someone entered their section of the cave. This stands in contrast to most temperate climate hibernators who, with much colder torpid body temperatures, are usually unresponsive to both noise and touch. In addition, the bats remained torpid throughout the study period and did not show the occasional periods of rewarming that are characteristic of almost all hibernators studied to date. It is unclear whether this is the result of the relatively high torpid body temperatures or the high humidity - and associated low water losses - allowing them to forgo rewarming for a drink. What is clear is that hibernation at a relatively high temperature is optimal for these species, allowing them to remain in sheltered caves throughout the cold winter while staying relatively alert to potential predators; a useful trait when living close to the cave entrance.

\subsection{2/jeb. 112508}

Levin, E., Plotnik, B., Amichai, E., Braulke, L. J., Landau, S., Yom-Tov, Y. and Kronfeld-Schor, N. (2015). Subtropical mouse-tailed bats use geothermally heated caves for winter hibernation. Proc. R. Soc. B 282, 20142781.

Danielle L. Levesque University of Malaysia at Sarawak Ildanielle@ibec.unimas.my

\section{Sunbathing helps senior flies keep active}

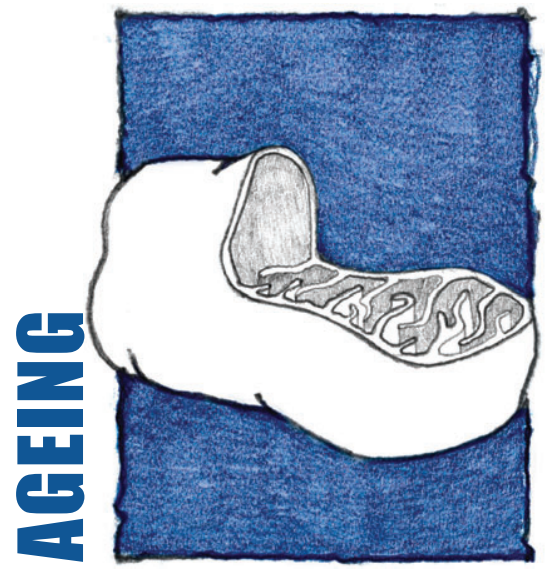

Living well into their senior years is a dream for many people. As animals age, their mitochondria progressively become less functional; they produce less energy in the form of adenosine triphosphate (ATP) and more inflammatory compounds such as reactive oxygen species (ROS). Keeping active and continuing your favourite activities for the majority of your golden years is tricky, but a new study using the model species fruit fly Drosophila melanogaster suggests that exposure to near-infrared light - that's red light on the very end of the visible spectrum - might help out.

Cytochrome $c$ oxidase is a key enzyme in the electron transport chain in the mitochondria, responsible for pumping protons across the mitochondrial

Outside JEB is a monthly feature that reports the most exciting developments in experimental biology. Articles that have been selected and written by a team of active research scientists highlight the papers that JEB readers can't afford to miss. 